\title{
Close Corporations and the Financing of SMEs: An Introduction
}

\author{
Paolo Giudici ${ }^{1} \cdot$ Joseph A. McCahery ${ }^{2}$
}

Published online: 20 November 2019

(c) T.M.C. Asser Press 2019

The articles in this special half issue deal with the financing gap that affects European firms. This problem is particularly worrisome because it concerns two key areas of European development and economic growth. The first involves the creation and scaling up of innovative startups. The second is access to finance by established small to medium-sized firms (SMEs), which are the backbone of the European and emerging market economies.

In recent years, policy makers and researchers have turned their attention to the growing array of legislative and financial market reforms that influence the creation of startups and their access to external sources of financing. While much previous research has focused on the introduction of new forms of private company law, scholars are redirecting their attention to the reform of the continental European model in light of the perceived competition from Delaware. In their attempt to understand the key features of the US model, researchers have sought to answer some basic questions: What are the key features of Delaware law that favour startup financing? How important is the contractual structure of startups to venture capitalists, angel investors and other institutional investors? What governance measures influence the long-term performance of innovative firms and startups?

The first article in this special issue, which arose from a research project cofinanced by the EGTC Tyrol-South Tyrol-Trentino and the universities of BolzanoBozen, Trento and Innsbruck, seeks to answer these questions. Giudici and Agstner's piece begins by looking at startups, which are a particular type of close corporations (Giudici and Agstner 2019). In general, close corporations are typically, at least in Europe, family firms. They have a partnership-like structure, and the relationship among shareholders is very personal. In contrast, startups are private firms with a different set of characteristics, including external investors. In terms of the business

Joseph A. McCahery

j.a.mccahery@uvt.nl

Paolo Giudici

paolo.giudici@unibz.it

1 Faculty of Economics, University of Bolzano, Bozen-Bolzano, Italy

2 School of Law, Tilburg University, Tilburg, The Netherlands 
financing cycle, early stage investors for startups are FFFs (Family, Fools, and Friends); then Angels, wealthy individual investors who operate alone or through investment networks (Angel Groups); and, finally, venture capital funds (VC). In many cases, VC financing deals in the US are very complex, and the complexity reflects the economics of a contract in which the risk of moral hazard rules. To meet these challenges, VCs will attempt to bind the entrepreneur to his or her promise of working hard for value creation. Thus, what is clear is that corporate law is an essential component of VC deals, and US law (and, in particular, Delaware Corporation Law) has sufficiently allowed freedom of contract to flourish almost undisturbed.

Taking the US experience as a reference point, Giudici and Agstner discuss how, from a European perspective, the Italian reforms over a five-year period radically changed the law of the Società a responsabilità limitata (SRL), the Italian equivalent of the German Gesellschaft mit beschränkter Haftung $(\mathrm{GmbH})$. According to Giudici and Agstner, the competitive pressure from US corporate law (Delaware's, in particular) may have prompted the introduction of greater flexibility in the organizational forms of Italian businesses. Understandably, expatriated Italian scientists and entrepreneurs and expatriated Italians in the finance world, wishing to return to Italy, were looking for an equivalent of the Delaware corporation and could not find one. In the absence of such an equivalent, the Italian legislator relied on a piecemeal approach to radically alter Italy's form of corporate law. So, how, then did the rules change to create more financial flexibility? Together, the elimination of the legal capital requirements for the SRL, as well as the possibility of issuing classes of 'quotas' and offering them to the public provided the financial flexibility, which startups required. In effect, the Italian legislator's relaxation of the rules silently turned the SRL on its head: it took the rules in the opposite direction from the historical process that in Continental Europe, under the influence of the German $\mathrm{GmbH}$, had led to the adoption of a two-model law-one for the public company and one for the private company. It is natural to question whether any changes in such a well-established framework make sense. After all, the new law left some issues to be dealt with: remaining mandatory provisions, as well as a large body of doctrines and beliefs that support a restrictive interpretation of freedom of contract and, thus, detract from the competitiveness of companies-a cultural process that is almost impossible to achieve without a clear, straightforward policy statement in favour of freedom of contract by the legislature, able to provide one single direction to all the actors involved (courts, lawyers, public notaries, etc.). Accordingly, Giudici and Agstner advance some proposals on how to successfully complete the Italian experiment, advocating reforms that would detach the Italian SRL from the family of the $\mathrm{GmbH}$ progeny. Whether these proposals will be followed or not, at the European level, the article shows that the huge appetite for startups might stretch the $\mathrm{GmbH}$ model to its breaking point, thereby raising doubts about the surviving raison d'être of the two-law system. We will return to this point below.

The discussion thus far has focused on the recent Italian company law reforms and how there is still considerable room for legislative changes that can enhance flexibility and, in turn, the performance of young and innovative companies. The next two papers in this special issue address the financing of small and mediumsized enterprises that are particularly dependent on credit and cash flows. Prior 
evidence on the financing of SMEs, both worldwide and from Europe, points out that SMEs appear to be severely underfunded. Much of this work shows that the sector is extremely sensitive to external market shocks, such as changes in economic regulation or severe economic conditions. This higher sensitivity to external market shocks is an important factor limiting SMEs' access to external finance. In turn, SMEs face financial constraints to the extent that they have weaker financial structures and have typically found it difficult to provide high-quality collateral or to ensure their creditworthiness.

In the second article, Godke Viega and McCahery show how the banking sector in an emerging market, such as Brazil, can negatively affect the availability of debt financing for SMEs (Godke Viega and McCahery 2019). Researchers studying these obstacles have suggested that access to credit may be affected by differences in both capital structure and performance. Also, differences in access to external finance may arise due to the size of companies, which can lead to market distortions since SMEs find it difficult to credibly send market signals about their projects to investors. At the same time, competition in the banking sector and differences in the institutional and legal structures can play a major role in SMEs' access to financing. Godke Viega and McCahery look at data from the Central Bank, the government statistical office and private organizations to determine the size of the financing gap for SMEs. They find evidence that the Brazilian loan gap was, on average, 27\% of GDP in the most important sectors of the economy between 2014 and 2016. It should be acknowledged that the presence of smaller and young firms in many jurisdictions may be one of the main determinants of SMEs' access to external finance. This phenomenon is apparent throughout both developing and developed countries and remains a significant problem for policy makers who seek to improve the flow of debt and equity to SMEs by introducing new incentives for promoting non-bank financing alternatives.

In this context, the third article in this issue, which originated from a Euregio research grant, concerns the innovative financing of SMEs in Europe. Boreiko, Ferrarini and Giudici investigate the European regulatory approach to initial coin offerings (ICOs) or initial exchange offerings (IEOs) (Boreiko et al. 2019). The authors argue that the distinction among different types of tokens that is currently followed in the literature and by regulators is somehow confusing. In particular, the three authors argue that utility tokens issued in ICOs or IEOs have elements of a minicurrency and an investment in a platform. Boreiko and coauthors analyse the capital markets' features of cryptocurrency markets and the capital markets' features in cryptocurrency investing to argue that ICO or IEO tokens are tradable securities in accordance with EU financial markets regulation, since they are negotiable on capital markets and present an investment component and a financial risk. Overall, a comparison of the European and US exemptions confirms that there is an urgent need to readapt current European Prospectus rules in order to ensure, under controlled conditions, access to capital markets to firms that want to go crypto.

The papers leave us with some open questions for future research. First, it can be argued that European regulators have made little effort to undertake reforms to attract foreign incorporations. As Giudici and Agstner argue, there is still very little understanding in Europe of the competitive pressures stemming from 
Delaware law. For example, Italian startups have obvious financial incentives to operate a company under foreign law. Despite the obvious advantages that Delaware law offers entrepreneurs, there has been little regulatory reform in Europe designed to enhance productivity for such firms. In fact, the Italian experience has revealed shortcomings in the two-law system, most notably in its weak support for young and innovative companies. Thus, Italy could become a sort of policy experiment, with the demise of the $\mathrm{GmbH}$ form or, perhaps, the liberalization of the public company in terms of management and capital provisions (within the limits imposed by the EU directives), leading to the reunification of company law with a single enabling model that could reduce costs and promote competition. Alternatively, the creation of a US-like LLC would increase firms' capacity to exploit the economic benefits offered by private ordering.

The second issue concerns the regulatory treatment of alternative forms of financing. As the articles show, there is a tradeoff between retail investor protection and the cost of access to capital markets. On the one hand, despite significant risks that ICOs pose to investors, only small parts of a huge regulatory framework apply to disclosure obligations and enforcement See, e.g. OECD (2019). On the other hand, in the US, qualified investors have financed some of the most important ICOs that, in Europe, would have been treated as retail and, thus, disallowed from participating in such offerings. But, as Boreiko and coauthors highlight, the prospectus regulation probably needs a general policy revision. Meanwhile, it appears that the prospectus and the $\mathrm{GmbH}$ company are two faces of the same regulatory problem-namely, investor protection.

The third issue concerns whether the rapidly growing financial sector will lead to more capital flowing to SMEs. For instance, Godke Viega and McCahery show that the development of new sources of finance could help to fill the financing gap. More specifically, there is clear evidence that platform lending is an attractive source of finance for different types of entrepreneurs. Perhaps unsurprisingly, there are a fair number of concerns about liquidity and regulation that will require redress before digital platforms and the alternative financing sector can become a reliable source of financing for small companies See, e.g. Leboeuf and Schwienbacher (2018). However, one may wonder how securities regulation, which remains important for sorting out this type of problem, can solve the new issues with an approach largely rooted in the 'lack of liquidity'.

The fourth issue concerns prospectus regulation and, more in general, securities regulation. If ICOs and IEOs continue, an effort might become necessary to rethink securities regulation or, at least, readapt it to this new phenomenon. As Boreiko and his coauthors have shown, tokens blur the traditional distinctions between currencies, securities, utility goods, and together with the blockchain technology might transform the traditional features of capital markets as we know them.

Finally, the papers in this special half issue have revealed the extent to which the financing gap has affected the ability of firms to increase growth and development for society overall. In Europe, there are few alternative financing channels available for SMEs. However, a number of market products (EY 2018), such as variable funding notes and forward flow arrangements, have begun to provide SMEs with a more 
diversified set of financing options that could enhance productivity and employment growth.

\section{References}

Boreiko D, Ferrarini G, Giudici P (2019) Blockchain startups and prospectus regulation. Eur Bus Org Law Rev. https://doi.org/10.1007/s40804-019-00168-6

EY (2018) UK bridging market survey: a view for 2018 and beyond. London. https://www.ey.com/Publi cation/vwLUAssets/EY-UK-bridging-market-study-2018-and-beyond/\%24FILE/EY-UK-bridgingmarket-study-2018.pdf. Accessed 18 Oct 2019

Giudici P, Agstner P (2019) Startups and company law: the competitive pressure of Delaware on Italy (and Europe?). Eur Bus Org Law Rev. https://doi.org/10.1007/s40804-019-00163-x

Godke Viega M, McCahery JA (2019) The financing of small and medium-sized enterprises: an analysis of the financing gap in Brazil. Eur Bus Org Law Rev. https://doi.org/10.1007/s40804-019-00167-7

Leboeuf G, Schwienbacher A (2018) Crowdfunding as a new financing tool. In: Cumming D, Hornuf L (eds) The economics of crowdfunding: startups, portals and investor behavior. Palgrave Macmillan, London, pp 11-28

OECD (2019) Initial coin offerings (ICOs) for SME financing. Paris. http://www.oecd.org/finance/initi al-coin-offerings-for-sme-financing.htm. Accessed 30 Oct 2019

Publisher's Note Springer Nature remains neutral with regard to jurisdictional claims in published maps and institutional affiliations. 